\title{
PEDIATRIC EDITORIAL
}

\section{Childhood obesity: time to shrink a parent}

International Journal of Obesity (2010) 34, 1-3; doi:10.1038/ijo.2009.200

An observer from another planet might well be confused by the dramatic increase in obesity, and our responses to it, over the past 30 years, ${ }^{1}$ soaring above the WHO criteria for a nutritional epidemic ${ }^{2}$ overtaking smoking as the leading cause of Coronary Heart Disease (CHD), ${ }^{3}$ and committing most of the current generations to chronic ill health and disability. Our interplanetary observer could see how a protracted process of excess fat accumulation leads to multiple organ-specific pathologies, and to vast attributable health-care expenditure. Hence, it is a disease alright, the consequence of gene-environment interactions and long established as ICD-9: 278. It is not to be trivialized as an expression of personal greed and an idle life. Obesity is also observably socially defined, emerging on an epidemic scale, perhaps as an unplanned product of an unregulated free market. ${ }^{4}$

Obesity arises from our actions but are these actions pathological? Barbara Wooton's classic definition of social pathology is 'all those actions on the prevention of which public money is spent'. ${ }^{5}$ Certain small public-sector elements certainly spend money on attempts to prevent obesity, but our observer, or an earthly cynic, might suggest that obesity actually contributes positively to the global economy (greater food consumption, bigger clothes, labor-saving devices, motorized transport, even incomes generated by variably effective treatments and token gym memberships). All of these create 'wealth'. Therefore, it is not surprising that prevention budgets are orders of magnitude less than the marketing of budgets for individual carbonated drinks or chocolate bars, or that sports fields are sold for building, roads are widened without cycle or pedestrian tracks and that portion sizes increase. Are current efforts at obesity management and prevention expressions of cynical tokenism?

Although almost all costs and impairment in Quality of Life associated with obesity develop in overweight and obese adults, the major emphasis in current national obesity strategies is directed toward 'childhood obesity'. In the United Kingdom, for example, the most recent White Paper on Public Health for England ${ }^{6}$ sets a target for reducing 'childhood obesity' (at age 11), but none for adults. The 2008 UK Cross-Government Obesity Strategy reiterates the primary target to reduce childhood obesity and includes nine action points directed at children, eight general actions and only two directed specifically at adults with obesity. ${ }^{7}$ The NICE guideline includes four pages on preventing childhood obesity, compared with two specifically on adults. ${ }^{8}$ The US Surgeon General's Office launched a prominent specific initiative for childhood overweight and obesity prevention in 2007. ${ }^{9}$ The underpinning thinking behind this focus is a belief-based view that preventing childhood obesity will lead to lifelong behavioral changes, and ultimately to arresting the epidemic of (adult) obesity. Evidence-based detractors have pointed out that over $80 \%$ of obese adults were not overweight as children, ${ }^{10-12}$ and that the tracking of overweight/obesity and of physical activity pattern, from childhood into adulthood, is weak until teenage years. ${ }^{13}$ Furthermore, 'obese' children, as per the currently defined (BMI >95) centile for 1990, are mostly only 'overweight', not 'obese', when they reach the age of 16-18 years. There is no evidence that preventing childhood obesity will reduce subsequent adult obesity, which is where virtually all health consequences and costs lie, and the evidence for efficacy, effectiveness or cost-effectiveness of interventions for childhood obesity is weak, lacking or negative. ${ }^{14,15}$ We can learn from these studies directed at children, and build on successful elements,, but the focus looks fundamentally flawed.

The Early Bird project, led by Wilkin, has previously produced observational evidence that children tend to compensate automatically for a high or low amount of physical activity provided in school, so that they all end up doing the same. ${ }^{16}$ They have also added to the evidence that greater physical activity in children protects against metabolic problems, but it has little effect on weight gain. ${ }^{17}$ The emerging argument for reducing the emphasis on children for obesity prevention is further strengthened by their new data (Perez-Pastor et al. ${ }^{18}$ ), from which it seems that the increase in childhood obesity over the past 20 years is in fact a simple ghastly consequence of increasing obesity in parents. They found that body composition is transmitted equally strongly from mother to daughter and from father to son, but much less to children of the opposite sex, such that the modern phenomenon of childhood obesity develops mainly as a sympathetic consequence of having a fat parent of the same sex. Unless some very unusual sex-linked genes operate, the relationship cannot be genetic. They observe that normal-weight parents are much less likely to have overweight children, and no more likely now than in 1990. 
It is well known that fat parents tend to have fat children, or children who ultimately become obese, ${ }^{19}$ but surprisingly previous research has not looked for an interaction between BMI and sex on the influence of parents on fatness of children. The results of Perez-Pastor are very striking: the shapes of 5-8-year-old children follow those of their same-sex parent, and only of that parent. The strength of the interaction makes it curious that this has not been shown before. Explanation may lie in the high overall prevalence of obesity in their contemporary data set, whereas the interaction may have been less clear in older cohorts. Shreds of evidence exist - for example, Fogelholm ${ }^{20}$ found that obese girls had more overweight mothers and obese boys had more overweight fathers than did normalweight children, but the relationship was not consistent in all analyses. The relationship needs to be checked in other contemporary data sets, with more reliable indicators of body fat than BMI, and explained either in psychological and behavioral forms or by novel concepts of genetic transfer and expression.

The notion that boys follow fathers and girls follow mothers resonates with somewhat archaic concepts of anthropology, and could even find favor with creationists, as it cannot be explained either by any conventional genetic/Mendelian mechanism. It is probably oversimplistic to suggest that genes affecting body composition arise in the $\mathrm{X}$ and $\mathrm{Y}$ chromosomes, but possibilities may open up through the growing work on epigenetics. A number of genes, including several relevant to energy balance and body composition, are 'imprinted' - commonly by methylation-and the maternally or paternally inherited genes may be expressed differently. It is an abnormality in paternally expressed imprinted genes on chromosome 15, which cause hyperphagia and obesity in the Prader Willi Syndrome. $^{21}$ There may be a tissue-specific expression of imprinted genes, and opposite physiological consequences can arise in the case of mutation or altered methylation, and expression of the maternal or paternal allele. This fascinating field has been expertly reviewed by Weinsten, ${ }^{22}$ explaining the potential for imprinted genes, particularly GNAS, in regulating fetal and postnatal growth. Expression of the maternal allele tends to limit fetal growth, whereas the paternal allele has the opposite effect. Postnatally, these influences are reversed, such that paternal allele expression is associated with leanness, but the maternal allele then promotes a positive energy balance and obesity, probably by reducing the sympathetic tone, with a secondary adverse impact on metabolic risk factors-echoing the Barker hypothesis. Genomic imprinting has not yet been shown to result in differential effects by the gender of offspring, but our understanding is very incomplete. Methylation is relatively easy to study, but imprinting may be mediated by histones, and further downstream proteo-glycan formation can modify the peptide structure and function. There is huge scope for environmental influence to modify growth and development by the modulation of gene expression.
There has been renewed recent interest in the observation that maternal overfeeding may influence imprinting, to promote positive energy balance with obesity and related metabolic abnormalities in offspring. The possible explanations could include some form of 'metabolic imprinting' to influence neural development, ${ }^{23}$ but genomic imprinting would probably have to be invoked if metabolic changes persist over subsequent generations. ${ }^{24}$ Genomic imprinting was invoked much earlier to explain the phenomenon whereby exposure to nitrosamines in smoked cured mutton or streptozotocin in pregnancy leads to small size and diabetes in mainly male offspring for several generations. ${ }^{25,26}$ These studies may also have revealed the possibility for differential effects by gender of offspring.

The inescapable conclusion, or extrapolation from Perez-Pastor et al., ${ }^{18}$ is that childhood obesity derives most importantly from the same-sex parent. If the relationship is behaviorally, psychologically or socially mediated, then interventions must be directed at the overweight parent. Childhood obesity should then really be viewed as an epiphenomenon, and not as the primary problem on which we should be spending more to prevent. In that case, childhood obesity itself should respond best to interventions directed not at children themselves, or at schools, but at families (which is already borne out by evidence). There is no evidence yet that effective weight management for parents will have a 'knock-on' effect on the BMI centiles of (same sex) children, but this now seems plausible, as might effective measures to lose excess fat gained by many mothers during pregnancy. If, on the other hand, same-sex inheritance of childhood obesity is mediated by subtle alterations in the expression of imprinted genes, solutions will be more complicated. If that is caused by parental obesity or hyperphagia in pregnancy in humans, as in experimental animals, $^{26}$ then avoiding obesity in parents, specifically restricting weight gain in pregnancy, will still help. The evidence on humans does somewhat support this notion. ${ }^{27}$ Obese parents do have more obesity-prone children, ${ }^{19}$ and dietary energy restriction in pregnant women does lead to smaller offspring, which is not explained by lower circulating nutrient concentrations. If the process is mediated by altered imprinting, then therapeutic modification of methylation would provide a mechanism to avoid childhood obesity, although there is enormous scope for unexpected and unwanted other consequences from treatments in pregnancy.

Even if the results of Perez-Pastor are ultimately disproved, common sense and years of observation indicate to us that parents are best somewhere near the size and shape they have been in throughout our successful evolution as a species. Most could do with shrinking.

MEJ Lean

Faculty of Medicine, Human Nutrition Section, Division of Developmental Medicine, University of Glasgow, Glasgow, UK E-mail: lean@clinmed.gla.ac.uk 


\section{References}

1 Ford ES, Mokdad AH. Epidemiology of obesity in the Western Hemisphere. J Clin Endocrinol Metab 2008; 93: S1-S8.

2 World Health Organisation. Obesity: Preventing and Managing the Global Epidemic. WHO: Geneva, Switzerland, 1998.

3 Mokdad AH, Marks JS, Stroup DF, Gerberding JL. Actual causes of death in the United States, 2000. JAMA 2004; 291: 1238-1245.

4 Sturm R. The economics of physical activity. Societal trends and rationales for interventions. Am J Prev Med 2004; 27: 126-135.

5 Wooton B. Social science and social pathology. George Allen \& Unwin 1959; p14.

6 Choosing Health: Making healthy choices easier. http:// www.dh.gov.uk/en/Publicationsandstatistics/Publications/ PublicationsPolicyAndGuidance/DH_4094550.

7 Healthy Weight, Healthy Lives A Cross Government Strategy for England. http://www.dh.gov.uk/en/Publicationsandstatistics/ Publications/PublicationsPolicyAndGuidance/DH_082378.

8 NICE. http://www.nice.org.uk/CG43.

9 US Office of the Surgeon General. Overweight in children and adolescents. January 2007 http://www.surgeongeneral.gov/ topics/obesity/calltoaction/fact_adolescents.htm.

10 Herman KM, Craig CL, Gauvin L, Katzmarzyk PT. Tracking of obesity and physical activity from childhood to adulthood: the physical activity longitudinal study. Int J Pediatric Obes 2008; 15: $1-8$.

11 Deshmukh-Taskar P, Nicklas TA, Morales M, Yang SJ, Zakeri I, Berenson GS. Tracking of overweight status from childhood to young adulthood: the Bogalusa Heart Study. Eur J Clin Nutr 2006; 60: $48-57$.

12 Janssen I, Katzmarzyk PT, Srinivasan SR, Chen W, Malina RM, Bouchard C et al. Utility of childhood BMI in the prediction of adulthood disease: comparison of national and international references. Obes Res 2005; 13: 1106-1115.

13 Singh AS, Mulder C, Twisk JW, van Mechelen W, Chinapaw MJ. Tracking of childhood overweight into adulthood: a systemic review of the literature. Obes Rev 2008; 9: 474-488.

14 Taylor RW, McAuley KA, Barbezat W, Farmer VL, Williams SM, Mann JI. Two-year follow-up of an obesity prevention initiative in children: the APPLE project. Am J Clin Nutr 2008; 88: 1371-1377.

15 Hughes AR, Stewart L, Chapple J, McColl JH, Donaldson MD, Kelnar CJ et al. Randomized, controlled trial of a best-practice individualized behavioural program for treatment of childhood overweight: Scottish Childhood Overweight Treatment Trial (SCOTT). Pediatrics 2008; 121: e539-e546.

16 Mallon KM, Metcalf BS, Kirby J, Voss LD, Wilkin TJ. Contribution of timetabled physical education to total physical activity in primary school children: cross sectional study. BMJ 2003; 327: 592-593.

17 Metcalf BS, Voss LD, Hosking J, Jeffery AN, Wilkin TJ. Physical activity at the government-recommended level and obesityrelated health outcomes: a longitudinal study (Early Bird 37). Arch Dis Child 2008; 93: 772-777.

18 Perez-Pastor EM, Metcalf BS, Hosking J, Jeffery AN, Voss LD, Wilkin TJ. Assortative weight gain in mother-daughter and father-son pairs: an emerging source of childhood obesity. Longitudinal study of trios (EarlyBird 43). IJO 2009; 33: 727-735.

19 Abu-Rmeileh NME, Hart CL, McConnachie A, Upton MA, Lean MEJ, Wat GCM. Contribution of midparental BMI and other determinants of obesity in adult offspring. Obesity 2008; 16: 1388-1393.

20 Fogelholm M, Nuutinen O, Pasanen M, Myohanen E, Saatela T. Parent-child relationship of physical activity patterns and obesity. IJO 1999; 23: 1262-1268.

21 Horsthemke BJW. Mechanisms of imprinting of the Prader-Willi/ Angelman region. Amer J Med Gen Part A 2008; 146A: 2041-2052.

22 Weinstein LS, Xie T, Qasem A, Wang J, Chen M. The role of GNAS and other imprinted genes in the development of obesity. Int J Obes 2009; 34: 1-3.

23 Levin BE. The obesity epidemic: metabolic imprinting on genetically susceptible neural circuits. Obes Res 2000; 8: 342-347.

24 Diaz J, Taylor EM. Abnormally high nourishment during sensitive periods results in body weight changes across generations. Obes Res 1998; 6: 368-374.

25 Stowers JM, Ewen SBW. Possible dietary factors in the induction of diabetes and its inheritance in man, with studies in mice. Proc Nut Soc 1991; 50: 287-298.

26 Samuelsson AM, Matthews PA, Argenton M, Christie MR, McConnell JM, Jansen EH et al. Diet-induced obesity in female mice leads to offspring hyperphagia, adiposity, hypertension and insuline resistance. Hypertension 2008; 51: 383-392.

27 Lean MEJ, Sutherland HW, Garthwaite PH. Obesity and fat distribution. In: Sutherland HW, Stowers JM, Pearson DWM (eds). Carbohydrate tolerance in pregnancy and the newborn. IV Springer Verlag: Berline, 1989; 267-275. 